MIDPI

MOL2NET, International Conference Series on Multidisciplinary Sciences http://sciforum.net/conference/mol2net-03

sciforum

\title{
Standardization of commercial cinnamon essential oils by gas chromatography-mass spectrometry analysis
}

\author{
Antolín Cantó Catalá (E-mail: cancan@alumni.uv.es), M. Amparo Blázquez Ferrer (E- \\ mail: amparo.blazquez@uv.es) \\ Departament de Farmacologia. Facultat de Farmàcia. Universitat de València. Avda. Vicent Andrés \\ Estellés s/n 46100, Burjassot, Valencia
}

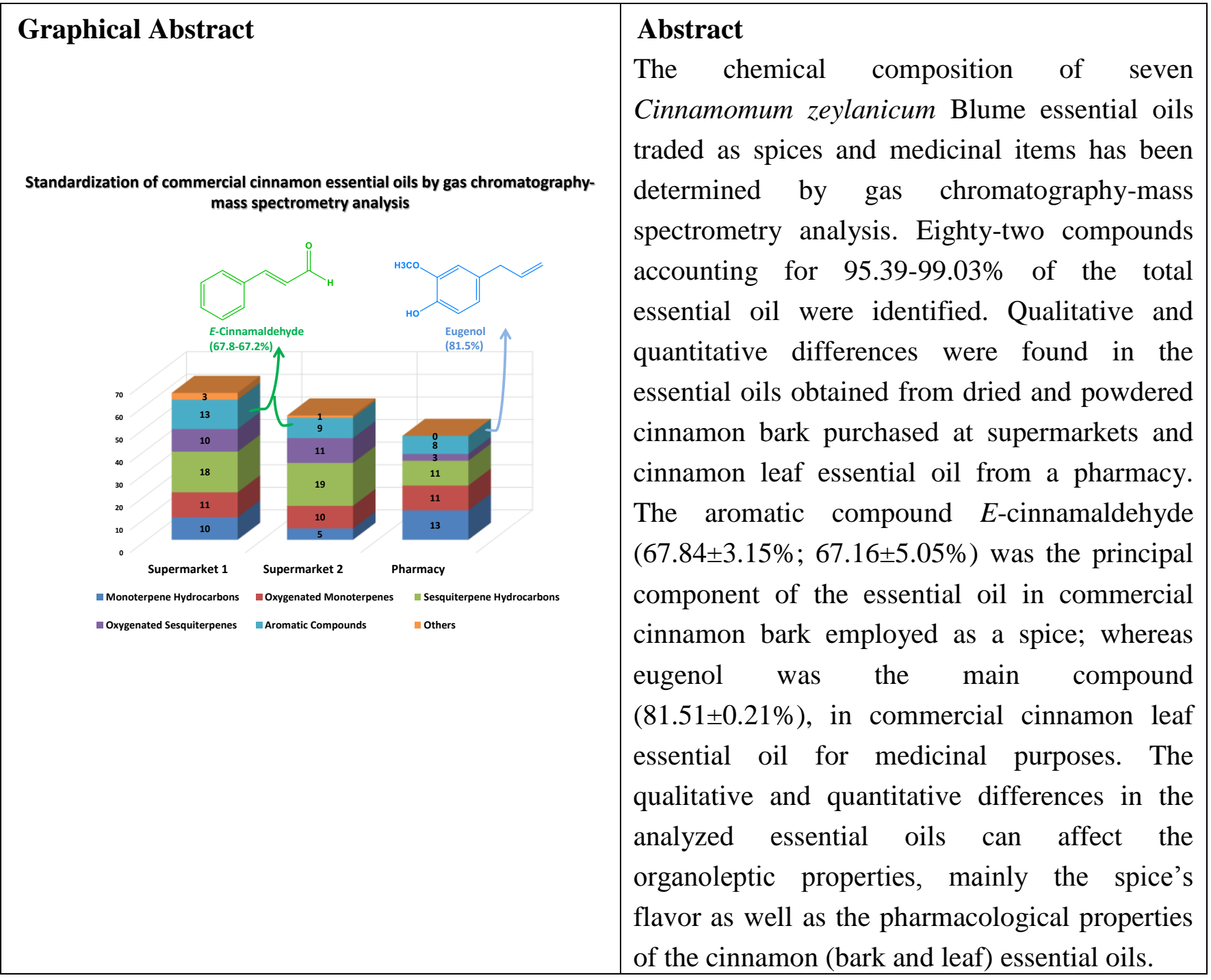

Nereis 9, pp. 13-24: https://www.ucv.es/investigacion/publicaciones/catalogo-de-revistas/revista$\underline{\text { nereis }}$ 